\title{
Article
}

\section{Thermal oscillations in the decomposition of organic peroxides: identification of a hazard, utilization, and suppression Rowena Ball}

Ind. Eng. Chem. Res., Just Accepted Manuscript • DOI: 10.1021/ie301070d • Publication Date (Web): 11 Dec 2012

Downloaded from http://pubs.acs.org on December 18, 2012

\section{Just Accepted}

"Just Accepted" manuscripts have been peer-reviewed and accepted for publication. They are posted online prior to technical editing, formatting for publication and author proofing. The American Chemical Society provides "Just Accepted" as a free service to the research community to expedite the dissemination of scientific material as soon as possible after acceptance. "Just Accepted" manuscripts appear in full in PDF format accompanied by an HTML abstract. "Just Accepted" manuscripts have been fully peer reviewed, but should not be considered the official version of record. They are accessible to all readers and citable by the Digital Object Identifier (DOI®). "Just Accepted" is an optional service offered to authors. Therefore, the "Just Accepted" Web site may not include all articles that will be published in the journal. After a manuscript is technically edited and formatted, it will be removed from the "Just Accepted" Web site and published as an ASAP article. Note that technical editing may introduce minor changes to the manuscript text and/or graphics which could affect content, and all legal disclaimers and ethical guidelines that apply to the journal pertain. ACS cannot be held responsible for errors or consequences arising from the use of information contained in these "Just Accepted" manuscripts. 


\title{
Thermal oscillations in the decomposition of organic peroxides: Identification of a hazard, utilization, and suppression
}

\author{
Rowena Ball \\ College of Physical and Mathematical Sciences \\ The Australian National University, Canberra ACT 0200 Australia \\ E-mail:Rowena.Ball@anu.edu.au
}




\begin{abstract}
The purpose of this research is to identify and characterise oscillatory thermal instability in organic peroxides that are used in vast quantities in industry and misused by terrorists. The explosive thermal decompositions of lauroyl peroxide, methyl ethyl ketone peroxide and triacetone triperoxide are investigated computationally, using a continuous stirred tank reactor model and literature values of the kinetic and thermal parameters. Mathematical stability analysis is used to identify and track the oscillatory instability, which may be violent. In the mild oscillatory regime it is shown that, in principle, the oscillatory thermal signal may be used in microcalorimetry to detect and identify explosives. Stabilization of peroxide thermal decomposition via Endex coupling is investigated. It is usually assumed that initiation of explosive thermal decomposition occurs via classical (Semenov) ignition at a turning point or saddle-node bifurcation, but this work shows that oscillatory ignition is characteristic of thermoreactive liquids and that Semenov theory and purely steady state analyses are inadequate for identifying thermal hazard in such systems.
\end{abstract}




\section{Introduction}

The objectives of this research were 1) to identify and characterise by mathematical stability analyses thermal oscillations that may initiate explosive thermal runaway during the thermal decomposition of liquid or solvated organic peroxides, 2) to carry out a preliminary feasibility study on exploiting oscillatory thermal instability in microcalorimetry to detect and provide thermal signatures of explosive materials, and 3) to investigate by simulation a potentially effective method of suppressing such oscillations via endothermic coupling, or Endex stabilization (which is described in the subsection 'Endex stabilization of organic peroxide decomposition' below). Three liquid or solvated organic peroxides were chosen for investigation: lauroyl peroxide (LP), methyl ethyl ketone (or 2-butanone) peroxide (MEKP), and triacetone triperoxide (TATP).

The motivation for this work is threefold.

Firstly, many accidental or unintended thermal runaway incidents involving organic peroxides occur in industry. Organic peroxides are are indispensable in a great many industrial processes and are manufactured, used, stored and transported in vast quantities. But fatalities and serious injuries from industrial peroxide explosions are common. Ho and Duh (1998) ${ }^{1}$ listed 10 explosion incidents involving organic peroxides that occurred in Taiwan between 1978 and 1996 and caused 56 fatalities, Liang et al. (2011) ${ }^{2}$ listed 7 MEKP explosions between 1964 and 1996 that occurred in Japan, Taiwan, China and Korea and caused 82 fatalities, Graham et al. (2011) ${ }^{3}$ listed 18 MEKP explosions from 1953 to 2007 collectively resulting in 102 fatalities and 332 serious injuries, and fatal peroxide explosions often occur in developing nations but are rarely reported in the Western press (Figure 1). The fact that these incidents continue to occur suggests that there may be a knowledge gap concerning thermal runaway criteria in reactive systems involving organic peroxides.

Secondly, peroxide explosives are increasingly being employed by terrorists as an ingredient in bombs and improvised explosive devices. They were used by the failed 2001 shoe bomber, in the suicide attacks on the London transit system in 2005, which killed 56 people, and were prepared and intended for use in the foiled 2006 transatlantic aircraft conspiracy. TATP is the most favoured explosive for such attacks. It is made by mixing acetone, hydrogen peroxide, and a bit 


\section{2 women killed in chemical factory explosion in city}

TNN | Aug 19, 2011, 04.32AM IST

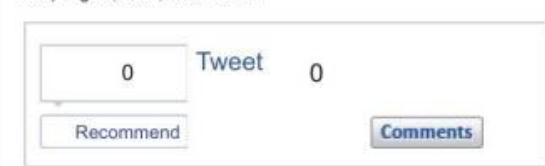

HYDERABAD: Two daily-wage workers died in an explosion at a chemical unit in Amberpet on Thursday morning.

The two victims were identified as Venkata Lakshmi, 45, and Kalpana, 30, of Venkatapuram Colony, who were working at Nagamani Chemicals owned by B Nanda Gopal from Bapu Nagar in Amberpet. The incident took place at 11.30am when the two workers were mixing hydrogen peroxide, methyl ethyl ketone and sodium sulphate to produce a chemical substance used in the manufacturing of asbestos sheet moulds and coolants. The high intensity of the explosion damaged a portion of the chemical unit's roof and severely injured both Venkata Lakshmi and Kalpana.

"With critical burn injuries, Venkata Lakshmi died on the spot and Kalpana succumbed to injuries while undergoing treatment at a nearby private hospital," Amberpet inspector A Srinivas said.

Police said that the chemical unit was an illegal one. Nanda Gopal, the owner of the unit, has been arrested and cases have been booked against him under section 304-A (Causing death due to rash or negligent act) of the Indian Penal Code (IPC).

Figure 1: Fatal incidents due to peroxide explosions that occur in the developing world are rarely reported in the Western press or picked up by Western occupational health \& safety incident databases. From The Times of India online, accessed 01 November 2012.

of sulfuric acid, all of which substances are legal, cheap and readily purchased over the counter or online with no questions asked. The recrystallized product looks like sugar, but incompetent fanatics intent upon terrorism need not carry out this step: the liquid mixture of acetone, $\mathrm{H}_{2} \mathrm{O}_{2}$ and acid can explode with devastating brisance. Peroxides cannot be detected by metal detectors and nitrogenous explosives detectors, or distinguished from hand lotion by X-ray machines, and to this day there are severe restrictions on carrying liquids through security barriers at most airports. Although intensive efforts have been made since 2001 to develop and improve methods of detecting peroxide explosives ${ }^{4}$ it seems grimly inevitable that their use as mass murder weapons will continue. Improved understanding of oscillatory initiation of explosive thermal runaway may help to counter this misuse. In this work it is proposed to exploit oscillatory thermal instability as a calorimetric diagnostic of suspected explosives.

Thirdly, given the potential of oscillatory instability to create serious thermal hazard, initiating thermal runaway, unintended thermal explosions, or worse, it is important to disseminate better 
understanding of it across those sectors of the chemical engineering community which deal with reactive thermal hazards and runaway criteria. Oscillatory instability can only be predicted by applying mathematical stability analysis to a dynamical model of the coupled temperature and reactant evolution. A steady state thermal balance, as is often used in the literature on thermal runaway and safety criteria, is necessarily blind to oscillatory solutions, as is Semenov (classical) ignition theory. In considering the thermal stability of a reacting system at a given steady state the paramount question we should ask is: Will a small perturbation to the temperature grow uncontrollably, or decay harmlessly? Answering this question necessarily involves the dynamics; i.e., a stability analysis using the well-founded mathematics of stability theory. The dangers inherent in prescribing thermal runaway criteria without carrying out a rigorous stability analysis were pointed out by Ball and Gray $(2012)^{5}$.

Thermal oscillations have been characterised by experiment and simulation in a variety of reacting liquid-phase systems; a collation is given in Table 1. In all cases listed the configuration was a continuous stirred tank reactor (CSTR), because it is an open flow system with non-trivial steady states that can be measured accurately and controlled finely. The CSTR is also widely used in industry, and a 'virtual' CSTR paradigm can be applied to identify oscillatory thermal runaway in batch setups or storage tanks ${ }^{6}$. It is relevant background to this work that self-sustained thermal oscillations have been observed experimentally during the decomposition of hydrogen peroxide in two independent studies ${ }^{7,8}$. Those measured by Wirges $(1980)^{8}$ had periods of $\sim 17-33$ minutes and $T_{\max }-T_{\min }$ amplitudes of $\sim 20-50 \mathrm{~K}$ for the range of conditions studied.

By elucidating oscillatory instability in the decomposition of organic peroxides we elicit new information about their explosive decomposition that is relevant to the storage, handling, and transport of these substances, and that may be exploited in thermal detection methods. In section 'Data, mathematical model and methods' the thermal decomposition of peroxides is discussed in general and a collection of experimentally measured kinetic and thermochemical data is tabulated, from which the data for the three peroxides investigated in this work are selected. The CSTR paradigm used in this work is discussed, the model equations are presented and the method of computing 
Table 1: Some CSTR systems in which thermal oscillations have been characterised in liquidphase reactions. E: experimental system, $\mathbf{S}$ : simulated system using published experimental data.

\begin{tabular}{|c|c|c|}
\hline & Reaction & Reference \\
\hline $\mathbf{E}$ & Hydrolysis of acetyl chloride in acetone-water solvent & Baccaro et al. (1970) ${ }^{9}$ \\
\hline E & $\begin{array}{l}\text { Decomposition of hydrogen peroxide by sodium thiosul- } \\
\text { fate in aqueous solution }\end{array}$ & Chang and Schmitz (1975) ${ }^{7}$ \\
\hline $\mathrm{E}$ & $\begin{array}{l}\text { Decomposition of hydrogen peroxide by } \mathrm{Fe}^{3+} \text { in } \mathrm{HNO}_{3} \\
\text { aqueous solution }\end{array}$ & Wirges $(1980)^{8}$ \\
\hline $\mathrm{E}$ & Acid catalysed hydration of 2,3-epoxy-1-propanol & $\begin{array}{l}\text { Heemskerk et al. }(1980),{ }^{10} \text { Vermeulen } \\
\text { and Fortuin }(1986)^{11,12}\end{array}$ \\
\hline E & $\mathrm{H}_{2} \mathrm{SO}_{4}$ catalysed hydrolysis of acetic anhydride & $\begin{array}{l}\text { Haldar and Phaneswara Rao (1991), }{ }^{13} \\
\text { Jayakumar et al. }(2011)^{14}\end{array}$ \\
\hline $\mathrm{E}$ & Oxidation of ethanol by hydrogen peroxide & Zeyer et al. (1999) ${ }^{15}$ \\
\hline S & Hydrolysis of methyl isocyanate & Ball $(2011)^{6}$ \\
\hline S & Thermal decomposition of cumene hydroperoxide & Ball $(2011)^{6}$ \\
\hline S & Nitration of glycerol to nitroglycerine & Ball and Gray $(2012)^{5}$ \\
\hline S & $\begin{array}{l}\text { Nitration of hexamine to cyclo- } 1,3,5 \text {-trimethylene-2,4,6- } \\
\text { trinitramine }\end{array}$ & Ball and Gray $(2012)^{5}$ \\
\hline
\end{tabular}

the steady states and analysing their stability is described briefly, and the model for a drifting or tunable ambient temperature is given. The main results that identify and characterise oscillatory thermal instability in decomposition of the peroxides are set out in the first three subsections of section 'Results'. The fourth subsection presents a feasibility study of using thermal oscillations as a calorimetric signature of peroxide explosives, and in the fifth subsection Endex principles are reviewed briefly and a feasibility study is made of Endex stabilization of peroxide decomposition thermal runaway. In the final section the findings of this work are summarized and conclusions stated. This article is complete in itself, but some technical and supporting material has been included in the associated online Supporting Information, available at pubs.acs.org.

\section{Data, mathematical model and methods}

\section{General remarks, kinetic and and thermochemical data}

Published experimental kinetic parameters and decomposition enthalpies for various organic peroxides are listed in Table 2.

The detailed mechanisms of thermal decomposition of organic peroxides are known to be very

6

ACS Paragon Plus Environment 
complex ${ }^{16}$, yet the measured kinetics often fit very well to a simple first-order rate law with Arrhenius dependence on temperature, suggesting that dissociation of the peroxide bond is the rate-determining step in most cases.

From transition state theory a unimolecular reaction can be expected to have a frequency factor, $A$, of around $10^{13} \mathrm{~s}^{-1}$ because that is the order of magnitude of $k T / h$ in the temperature range of most reactions, where $k$ is Boltzmann's constant and $h$ is Planck's constant ${ }^{17}$. Many of the frequency factors listed in Table 2 are indeed of order $10^{13} \mathrm{~s}^{-1}$. The larger frequency factors in Table 2 are for solvated peroxides. Certain solvents increase the rate due to induced decomposition, where radicals from the solvent attack the undissociated peroxide ${ }^{16}$.

There may be good reasons to expect the activation energies to be similar in value too, because the activation energy is identified with the homolytic dissociation energy of the peroxide bond, if that is the rate-determining step ${ }^{18,19}$. The differences in measured activation energies are accounted for by shifts in mechanism, substituent electronic and steric effects, and solvent effects ${ }^{16}$. Contamination with acid, base, metals, or amines has been shown to sensitise many peroxides, ${ }^{20,21}$ reducing the activation energy or switching the decomposition to a lower activation energy path.

Data missing from Table 2 but essential for this work are the specific heat capacities, $C(\mathrm{~J} /(\mathrm{kg} \mathrm{K}))$, of the peroxides. The heat capacities of some organic peroxides have been measured in the gas and solid phases, but heat capacity data for peroxides in liquid phase are scarce. Townsend and Tou $(1980)^{22}$ assume the average specific heat of a generic organic liquid over the temperature range $320-450 \mathrm{~K}$ to be $2092 \mathrm{~J} /(\mathrm{kg} \mathrm{K})$ and this is the value used in this work; the temperature dependence of the heat capacity is neglected. Diogo et al. (1995) ${ }^{23}$ measured the specific heat capacity of liquid di-tert-butyl peroxide as $2065 \mathrm{~J} /(\mathrm{K} \mathrm{kg})$ at $308 \mathrm{~K}$ and $2189 \mathrm{~J} /(\mathrm{K} \mathrm{kg})$ at $338 \mathrm{~K}$, which gives by linear regression $C=803.3+4.10 \times T \mathrm{~J} /(\mathrm{K} \mathrm{kg})$, so the value of $2092 \mathrm{~J} /(\mathrm{K} \mathrm{kg})$ seems reasonable to use over the temperature range of these studies. 
Table 2: Compilation of experimental kinetic parameters and decomposition enthalpies for various organic peroxides. Data from the starred * references are used in this work. DCP dicumyl peroxide, CHP cumyl hydroperoxide, DTBP di-tert-butyl peroxide, LP lauroyl peroxide, TBPA tert-butyl peroxyacetate, TBPB tert-butyl peroxybenzoate, TATP triacetone triperoxide, MEKP methyl ethyl ketone peroxide.

\begin{tabular}{llllll}
\hline \hline Peroxide & Reference & $n$ & $A\left((1 / \mathrm{mol})^{n-1} \mathrm{~s}^{-1}\right)$ & $E(\mathrm{~kJ} / \mathrm{mol})$ & $-\Delta H(\mathrm{~J} / \mathrm{g})$ \\
\hline DCP & 24 & 1 & $1.2 \times 10^{10}$ & 135 & 860.3 \\
DCP & 25 & 1 & $1.1 \times 10^{13}$ & 132 & 740 \\
DCP & 26 & 1 & $2.0 \times 10^{11}$ & 117 & 736 \\
CHP & 27 & 0.5 & $7.996 \times 10^{12}$ & 125 & 1810 \\
DTBP & 28 & 1 & $5.32 \times 10^{13}$ & 134.58 & 1100 \\
DTBP & 29 & 0.74 & $9.7 \times 10^{9}$ & 110 & 964 \\
LP & $30 *$ & $1-1.2$ & $0.07-8.1 \times 10^{12}$ & $90-100$ & 632 \\
LP & 31 & 1.28 & $7.056 \times 10^{14}$ & 124.05 & 599.59 \\
LP & 32 & 1 & $2.17 \times 10^{16}$ & 138 & \\
TBPA & 33 & 1 & $1.37 \times 10^{21}$ & 123.8 & \\
TBPB & 34 & 1 & $2.62 \times 10^{11}$ & 111.7 & 1266 \\
TATP & $35 *$ & 1 & $3.75 \times 10^{13}$ & 151 & 3402 \\
TATP & 36 & 1 & $9.57 \times 10^{16}$ & 178.52 & \\
MEKP & 37 & 1 & $6.370 \times 10^{11}$ & 116.69 & 1297.82 \\
MEKP & $38 *$ & 1 & $1.77 \times 10^{13}$ & 102.97 & \\
MEKP & $39 *$ & 1 & $1.0 \times 10^{13}$ & 117.730 & 483.206 \\
MEKP & $3 *$ & & & & 395 \\
\hline \hline
\end{tabular}

\section{The CSTR paradigm: model, equations and methods}

Self-heating reactive systems are often treated using the Semenov (classical ignition) paradigm, which uses the temperature as the only dynamical variable. Semenov theory was originally developed to explain explosive ignition of unstable solids, then extended to reacting gases at low pressure. For those systems it has stood the test of time very well, ${ }^{40}$ and it is noteworthy that the gas-phase decomposition of diethyl peroxide at low pressure was used as the first (and is still the best) experimental verification of Semenov explosion theory. ${ }^{41}$

In Semenov theory ignition always occurs at a turning point (limit point, saddle-node bifurcation) in the curve of steady state solutions, and no reference is made to oscillatory ignition because reactant depletion is ignored (the infinite pool approximation) and periodic solutions are automatically forbidden in a system evolving in just one dynamical variable. Semenov theory is insufficient for analysing open systems with reactant depletion, for which the steady states and their stability must be fully characterised. For such systems the CSTR paradigm is appropriate. 
In this work the peroxide decompositions are simulated using the physical parameters for the experimental CSTR from Heemskerk et al. (1980) ${ }^{10}$ and Vermeulen and Fortuin (1986). ${ }^{11,12}$ The dynamical mass and enthalpy equations that model this system are as follows:

$$
\begin{aligned}
M \frac{\mathrm{d} c}{\mathrm{~d} t} & =-M A \mathrm{e}^{-E / R T} c^{n}+F\left(c_{\mathrm{f}}-c\right) \\
\left(M \bar{C}+m C_{\mathrm{w}}\right) \frac{\mathrm{d} T}{\mathrm{~d} t} & =M(-\Delta H) A \mathrm{e}^{-E / R T} c^{n}-\bar{C} F\left(T-T_{\mathrm{f}}\right)-L\left(T-T_{\mathrm{a}}\right)+\dot{Q},
\end{aligned}
$$

where the initial concentration $c_{0}=c_{\mathrm{f}}$ and the initial temperature $T_{0}=T_{\mathrm{f}}$. Notation and quantities are defined in Appendix A, Table 6, where the numerical values of quantities that are fixed are also given.

The system defined by Eqs (1) and (2) may be treated as a real experimental CSTR, or it may be thought of as a 'virtual CSTR', circumscribing a reacting mass or volume that remains approximately constant and gradientless relative to the much faster rate of reaction. In characterising oscillatory thermal instabilities the focus is on the dynamics, and the reacting volume or virtual CSTR could be a small region inside a large vessel or storage tank, where spatial gradients are insignificant in comparison to the time evolution and can be neglected. If this approximation does not hold, then we are free to reduce the circumscribed volume until it does.

The advantage of the CSTR paradigm over a batch or semi-batch reactor description is that it has non-trivial steady states that can be analysed using stability and bifurcation theory. The steady state saddle-node bifurcations emulate Semenov ignition (and extinction), and as an open dissipative system in two dynamical variables the CSTR also has oscillatory solutions. For the case of a single first-order (or pseudo first-order) exothermic conversion in a CSTR the global point of onset of classical ignition has been calculated analytically ${ }^{42}$ and analysis combined with numerics have characterised the oscillatory states and identified thermal runaway due to the hard onset of oscillatory instability at a subcritical Hopf bifurcation. ${ }^{6,43}$

The kinetic parameters and enthalpy of decomposition from the starred entries in Table 2 for each of the peroxides studied in this work were used in Eqs (1) and (2). These experimental param- 
eter values were chosen because the kinetic constants are reasonably close to the values expected from theory, as discussed above under subsection 'General remarks, kinetic and and thermochemical data'. The values of the mass, specific heat and reactor parameters given in Table 6, Appendix A, were used. The mass flow rate $F$, combined heat loss coefficient $L$, inflow concentration $c_{\mathrm{f}}$, and inflow temperature $T_{\mathrm{f}}$ were adjusted as appropriate to the particular peroxide being studied.

The ambient or coolant temperature $T_{\mathrm{a}}$ was used as the bifurcation parameter, which is quasistatically varied. Equations (1) and (2) were integrated to a low-temperature steady state for a given parameter set, then the steady state curve over $T_{\mathrm{a}}$ was computed. At each steady state the corresponding linear eigenvalue problem was solved and the points where an eigenvalue changed sign were flagged. The system becomes unstable if such a sign change is positive. These flagged points are the bifurcation points: if a real eigenvalue becomes positive there is a saddle-node bifurcation, or classical ignition point, and if the real parts of a complex conjugate pair become positive the system exhibits a Hopf bifurcation and the onset of limit cycle oscillations. The resulting bifurcation diagram emulates the behaviour of the system under a slowly upwards drifting ambient temperature; some examples may be previewed in Figure 10, which is discussed in subsection 'Endex stabilization of organic peroxide decomposition' below.

Where a bifurcation point is identified, we can follow it by varying a second parameter. We allow the mass flow rate $F$ to vary as well as $T_{\mathrm{a}}$ and compute the loci of the Hopf and saddle-node bifurcations. The resulting curves are projected onto the $T_{\mathrm{a}}-F$ plane as two-parameter bifurcation diagrams; examples may be previewed in Figures 2, 4, 6 and 8, which are discussed below in the appropriate subsections.

Time series were also computed for a constant upwards drift or tuning of $T_{\mathrm{a}}$. This converts the 
CSTR system into the following dynamical problem:

$$
\begin{aligned}
M \frac{\mathrm{d} c}{\mathrm{~d} t} & =-M A \mathrm{e}^{-E / R T} c^{n}+F\left(c_{\mathrm{f}}-c\right) \\
\left(M \bar{C}+m C_{\mathrm{w}}\right) \frac{\mathrm{d} T}{\mathrm{~d} t} & =M(-\Delta H) A \mathrm{e}^{-E / R T} c^{n}-\bar{C} F\left(T-T_{\mathrm{f}}\right)-L\left(T-T_{\mathrm{a}}(t)\right)+\dot{Q} \\
\frac{\mathrm{d} T_{\mathrm{a}}}{\mathrm{d} t} & =\dot{q},
\end{aligned}
$$

where $\dot{q}$ is the drift or ramping rate and $T_{\mathrm{a}}$ is annotated to remind us that in Eq. (2) ${ }^{\prime}$ it is a function of time. As we shall see, the time series computed from Eqs (1), (2') and (3) for small $\dot{q}$ reflect the behaviour predicted in the two-parameter steady state bifurcation diagrams.

\section{Results}

\section{Lauroyl peroxide}

Lauroyl peroxide is a diacyl peroxide with the molecular formula $\left(\mathrm{C}_{11} \mathrm{H}_{23} \mathrm{CO}\right)_{2} \mathrm{O}_{2}$. It is widely used in industry as an oil-soluble initiator of polymerization that also acts to stabilize the monomer/water emulsion. ${ }^{20,44}$ You et al. (2009) ${ }^{30}$ studied the thermal decomposition of LP by DSC and found that melting (the endotherm) occurs at $40-45^{\circ} \mathrm{C}$ and thermal decomposition (the exotherm) sets in at $60-75^{\circ} \mathrm{C}$, with the maximum occurring at $92-118^{\circ} \mathrm{C}$. The averages of the kinetic parameters determined by You et al. (2009), ${ }^{30}$ given in Table 2, were used in this work: $A=4.1 \times 10^{12}$, $E=93 \mathrm{~kJ} / \mathrm{mol}$. (The data from You et al. (2010) ${ }^{31}$ were determined for LP mixed with $1 \mathrm{~N}$ nitric acid, and the data from Guillet and Gilmer (1969) ${ }^{32}$ were determined for $0.5 \% \mathrm{LP}$ w/v in mineral oil.)

Figure 2 shows the loci of critical or bifurcation points in the lauroyl peroxide decomposing system over $T_{\mathrm{a}}-F$, computed as described in the above subsection, 'The CSTR paradigm: model, equations and methods', using Eqs (1) and (2). The inflow concentration $c_{\mathrm{f}}=2.5 \mathrm{~mol} / \mathrm{kg}$ corresponds to almost pure lauroyl peroxide melting into the reaction zone at the melting temperature of $40^{\circ} \mathrm{C}$ as determined by the endotherm observed by You et al. (2009) ${ }^{30}$. 


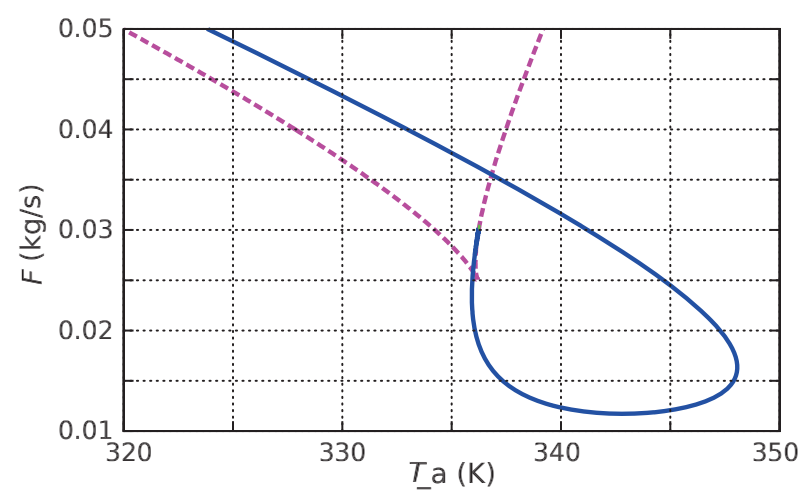

Figure 2: Loci of Hopf bifurcations (solid line, blue in color printed and online versions) and saddle-node bifurcations (dashed line, magenta in color printed and online versions) over $T_{\mathrm{a}}-F$ for thermal decomposition of LP in CSTR. Other parameters: $E=93 \mathrm{~kJ} / \mathrm{mol}, A=4.1 \times 10^{12} \mathrm{~s}^{-1}$, $c_{\mathrm{f}}=2.5 \mathrm{~mol} / \mathrm{kg}, L=300 \mathrm{~W} / \mathrm{K}, T_{\mathrm{f}}=313 \mathrm{~K}, \Delta H=-599590 \mathrm{~J} / \mathrm{kg}$,

The locus of Hopf bifurcations (solid curve) in Figure 2 looks like a 'J' written backhand. Within the large hook of the ' $\mathrm{J}$ ', and also near to the upper section of the Hopf locus, the system will develop self-sustained thermal oscillations, regardless of the initial conditions. The steady states in this region are unstable and the system must settle onto an alternative stable attractor, in this case a limit cycle. In the region enclosed by the saddle-node bifurcation locus (dashed curve) the system has two stable steady states between which is an unstable steady state. The hightemperature branch of the saddle-node locus represents the classical (Semenov) ignition points and the low-temperature branch represents the classical extinction points. The saddle-node curves can be obtained by considering only the steady states of Eqs (1) and (2), but because we have also computed the stability of the steady states we now know that thermal instability may occur over a broad region that is mostly at higher $T_{\mathrm{a}}$ than the classical ignition region.

What actually happens when the LP system is subject to a slowly increasing ambient temperature? Equations (1), (2') and (3) were integrated with $\dot{q}=0.0667 \mathrm{~K} \mathrm{~s}^{-1}$ from $T_{\mathrm{a}, 0}=313 \mathrm{~K}$, for five selected values of $F$, and the resulting time series are shown in Figure 3. We can distinguish several different scenarios for thermal runaway.

For $F=0.012 \mathrm{~kg} \mathrm{~s}^{-1}$ in Figure 3(a) the Hopf bifurcation locus is barely crossed but the onset of benign thermal oscillations at around $400 \mathrm{~s}$ is already evident at $T \sim 355 \mathrm{~K}$. However, the oscillations grow enormously in amplitude with only a small increase in $F$ as Figure 3(b) shows. For 

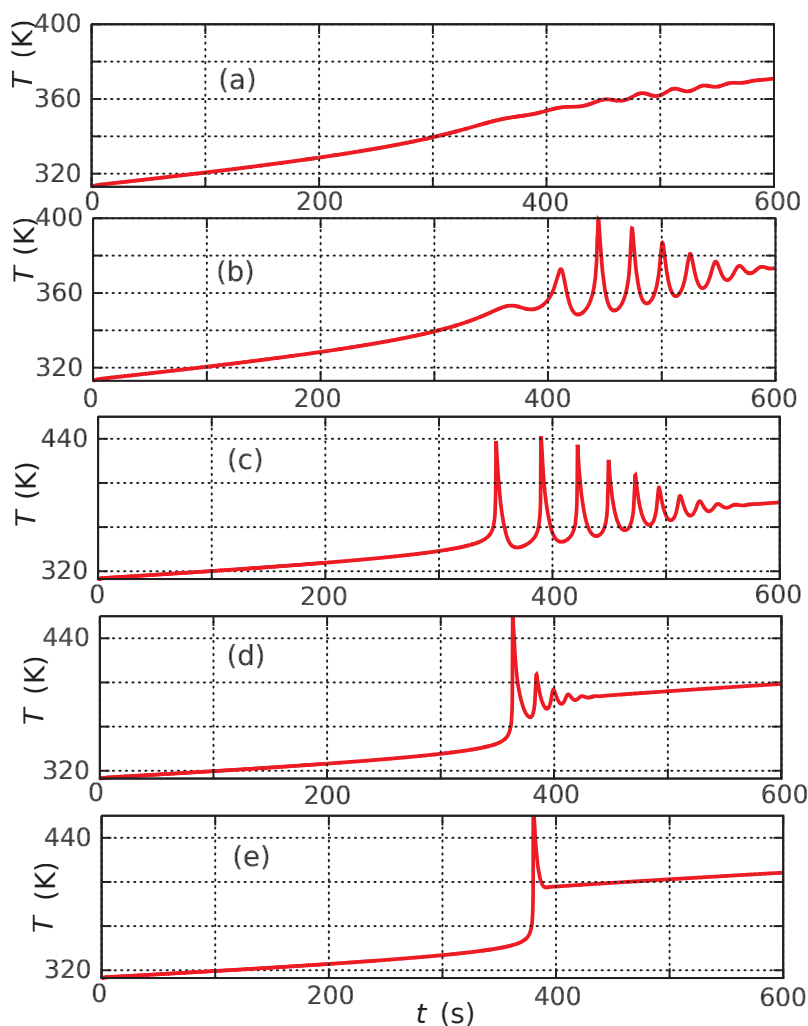

Figure 3: Time series for $\dot{q}=0.0667 \mathrm{~K} \mathrm{~s}^{-1}$ in the LP system. (a) $F=0.012 \mathrm{~kg} \mathrm{~s}^{-1}$, (b) $F=$ $0.014 \mathrm{~kg} \mathrm{~s}^{-1}$, (c) $F=0.020 \mathrm{~kg} \mathrm{~s}^{-1}$, (d) $F=0.032 \mathrm{~kg} \mathrm{~s}^{-1}$, (e) $F=0.040 \mathrm{~kg} \mathrm{~s}^{-1}$. Other parameters as for Figure 2.

(c), (d) and (e) the time to onset of ignition $t_{\mathrm{ig}}$, temperature at onset of ignition $T_{\mathrm{ig}}$, and $T_{\mathrm{a}}$, ig are tabulated in Table 3, as abstracted from the computed datasets.

Table 3: Critical onset times and temperatures from the computed datasets for (c), (d), and (e) of Figure 3.

\begin{tabular}{llll}
\hline \hline subfigure & $t_{\mathrm{ig}}(\mathrm{s})$ & $T_{\mathrm{ig}}(\mathrm{K})$ & $T_{\mathrm{a}, \text { ig }}(\mathrm{K})$ \\
\hline \hline (c) & 327 & 344 & 335 \\
(d) & 343 & 343 & 336 \\
(e) & 365 & 344 & 337 \\
\hline \hline
\end{tabular}

(The onset of ignition is defined, arbitrarily but conveniently, as the first temperature where $\mathrm{d} T / \mathrm{d} t>4 \dot{q}$. Note that this is not the same as the exotherm onset temperature in calorimetric experiments. Firstly, the temperature that is tuned in DSC experiments is analogous to $T_{\mathrm{a}}$ in this work, not the dynamical system temperature $T$. Secondly, the definition of experimental onset temperature is often instrument-specific. For example, in Graham et al. (2011) ${ }^{3}$ the onset temper- 
ature is defined as the temperature at which the heating rate exceeds the instrumental heating rate by $0.02^{\circ} \mathrm{C} / \mathrm{min}$, and is output by the instrument.)

For $F=0.020 \mathrm{~kg} \mathrm{~s}^{-1}$ in (c) we have full-blown oscillatory thermal runaway, with violent onset. At the higher inflow rate of $0.032 \mathrm{~kg} \mathrm{~s}^{-1}$ in (d) thermal runaway is also non-classical. Although the ignition is classical, because it occurs at the upper saddle-node bifurcation in Figure 2, the attractor to which the transient moves is a limit cycle, and the system must pass through an oscillatory regime as $T_{\mathrm{a}}$ increases quasistatically, and this behaviour is fully reflected in Figure 3(d). In (e) thermal runaway is purely classical, with the model system settling onto the upper stable steady state branch of solutions after the transient spike.

That the system will pass from stable through oscillatory behavior to classical thermal runaway as $F$ is increased, as shown in Figure 3, can be predicted from the two-parameter map in Figure 2: If we take a slice for $F$ below the minimum of the Hopf bifurcation locus and construct time series for any $T_{\mathrm{a}}$ we would expect them to be stable. A slice taken just above the minimum of the Hopf bifurcation locus will have oscillatory time series over a range of $T_{\mathrm{a}}$. This behaviour onsets at lower $T_{\mathrm{a}}$ for slices taken at successively higher $F$. For $F$ greater than about 2.5 we encounter the locus of saddle-node bifurcations and we would expect classical ignition to begin to dominate the oscillatory behaviour, as is reflected in Figure 3(e).

Physically, high-amplitude thermal oscillations occur at slow mass inflow rates because the system is reactant-limited. The average residence time $\tau=M / F$ is long and there is time for complete decomposition to occur, with concomitant spike in the temperature. At the temperature maximum reactant is almost fully depleted so the temperature declines on the dissipative timescale, but reactant is flowing in slowly and accumulating and the cycle begins again. At higher flow rates or short average residence times less reactant is consumed and the classical dynamics dominates.

In a real experimental system the high amplitude oscillation may not be observed, because the system would vent or rupture or would have to be quenched at the onset of thermal runaway to avoid rupture, but the low amplitude oscillations in Figure 3(a) and (b) could certainly be observed with careful management of conditions, as they have been observed for substances listed in Table 1. 


\section{Methyl ethyl ketone peroxide}

By all accounts this widely used industrial substance has very nasty explosive properties indeed. Graham et al. $(2011)^{3}$ found that MEKP is responsible for the highest number of reported destructive decomposition incidents of all the organic peroxides. MEKP is not a single compound but a mixture of up to 7 products derived from methyl ethyl ketone and hydrogen peroxide, some of which may interconvert in dynamic equilibrium. ${ }^{45}$ Commercial preparations consist mainly of the dimer, with the ratios of other peroxide species dependent on manufacturing and storage conditions. ${ }^{3}$ Since undiluted MEKP is regarded as extremely unstable it is usually supplied diluted in a high boiling inert solvent such as dimethyl phthalate (DMP).

Three exotherms are usually measured in calorimetric experiments on MEKP, due to separate decomposition reactions. ${ }^{3,38}$ The first (lowest temperature) exotherm is very small and is due to decomposition of the minor monomer component, the second is due to decomposition of the major component dimer, and the third exotherm is ascribed to reaction with solvent. With $1 \%$ sulfuric acid these collapse to a single exotherm. ${ }^{38}$ DSC onset temperatures for decomposition of the dimer occur in the range $70-122^{\circ} \mathrm{C}$, depending on heating rate. ${ }^{3}$ Slow heating of stored MEKP is a real possibility due to the presence of small amounts of the monomer, for which the exotherm onset occurs at only $30-56^{\circ} \mathrm{C}$.

Equations (1) and (2) were solved numerically for $c_{\mathrm{F}}=0.951 \mathrm{~mol} / \mathrm{kg}$, corresponding to $20 \%$ wt MEKP in solvent, and for two sets of kinetic parameters and decomposition enthalpies: (a) those measured by Yuan et al. (2005) ${ }^{39}$ for the second exotherm, starred in Table 2, and (b) kinetic parameters measured by Fu et al. (2003) ${ }^{38}$ and the average decomposition enthalpy measured by Graham et al. $(2011)^{3}$ for the second exotherm, starred in Table 2. The resulting two-parameter bifurcation diagrams are shown in Figure 4.

The J-curve of Hopf bifurcations is forward-slanting in (a) and fairly upright in (b). In contrast to the diagram in Figure 2 for LP, the oscillatory behaviour within the hook of the Hopf locus occurs mostly at lower $T_{\mathrm{a}}$ than the classical ignition/extinction behaviour within the region bounded by the saddle-node locus, this tendency being less pronounced in (b). It is notable, too, that the unstable 

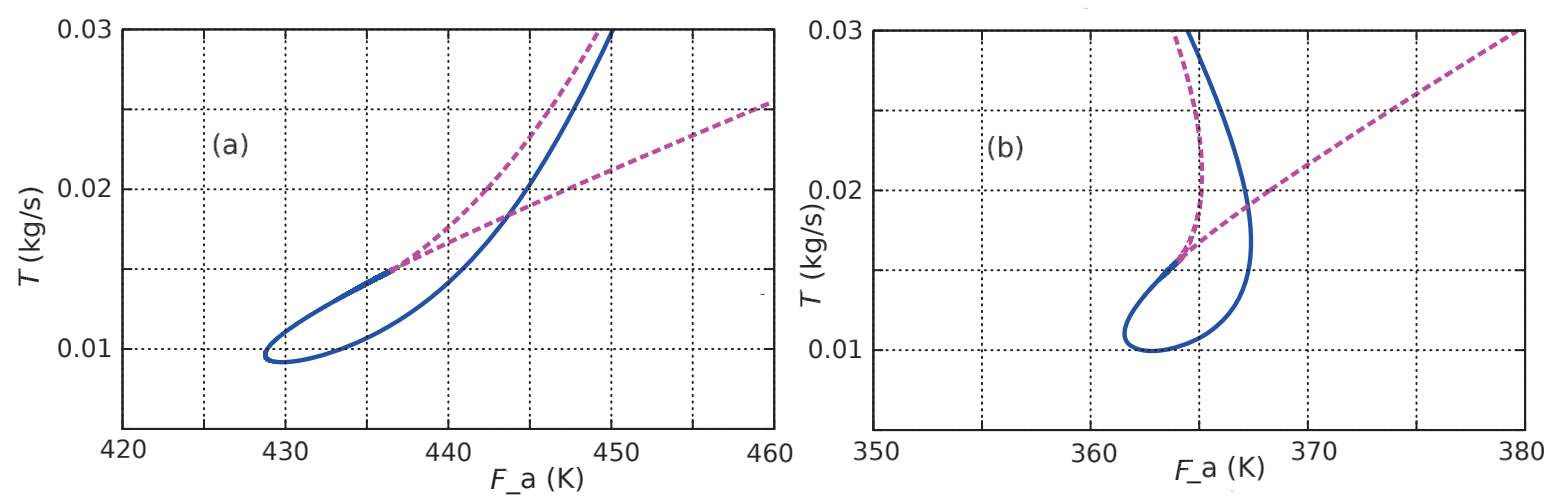

Figure 4: Loci of Hopf bifurcations (solid line, blue in color printed and online versions) and saddle-node bifurcations (dashed line, magenta in color printed and online versions) over $T_{\mathrm{a}}-F$ for MEKP decomposition in CSTR. (a) $A=1.0 \times 10^{13} \mathrm{~s}^{-1}, E=117.730 \mathrm{~kJ} / \mathrm{mol}, \Delta H=-484206 \mathrm{~J} / \mathrm{kg}$, (b) $A=1.77 \times 10^{13} \mathrm{~s}^{-1}, E=102.97 \mathrm{~kJ} / \mathrm{mol}, \Delta H=-395000 \mathrm{~J} / \mathrm{kg}$. Common to both (a) and (b): $c_{\mathrm{F}}=0.951 \mathrm{~mol} / \mathrm{kg}, L=100 \mathrm{~W} / \mathrm{K}, T_{\mathrm{f}}=298 \mathrm{~K}$.

regime in (b) occurs over a considerably lower temperature range, the low $T_{\mathrm{a}}$ extremum of the Hopf bifurcation curve occurring at only $362.5 \mathrm{~K}$, reflecting the lower activation energy.

Time series for the MEKP system of Figure 4(a) were obtained by integrating Eqs (1), (2') and (3) with $\dot{q}=0.0667 \mathrm{~K} \mathrm{~s}^{-1}$ for three values of $F$. The results are plotted in Figure 5 and relevant critical data abstracted from the computed datasets are given in Table 4. In Figure 5 we see similar qualitative behaviour to that for LP in Figure 3: in (a) the onset of thermal runaway is purely oscillatory, in (b) classical ignition occurs at a turning point but thermal runaway is non-classical, because the attractor is a limit cycle solution and the system passes through an oscillatory regime as $T_{\mathrm{a}}$ increases further, and in (c) ignition is purely classical.

Table 4: Critical onset times and temperatures from the computed datasets for Figure 5.

\begin{tabular}{llll}
\hline \hline subfigure & $t_{\text {ig }}(\mathrm{s}),(\mathrm{min})$ & $T_{\mathrm{ig}}(\mathrm{K})$ & $T_{\mathrm{a}, \mathrm{ig}}(\mathrm{K})$ \\
\hline \hline (a) & $1964,32.73$ & 419 & 431 \\
(b) & $2096,34.93$ & 419 & 440 \\
(c) & $2304,38.40$ & 419 & 454 \\
\hline \hline
\end{tabular}

As noted parenthetically in subsection 'Lauroyl peroxide', the temperature that is tuned in DSC experiments corresponds to the ambient temperature $T_{\mathrm{a}}$ in these simulations. Consideration of the 2-parameter bifurcation diagrams in Figure 4 and the $T_{\mathrm{a}}$, ig values in Table 4 may help to explain the wide range of onset temperatures of MEKP decomposition reported by Graham et al. (2011): ${ }^{3}$ 

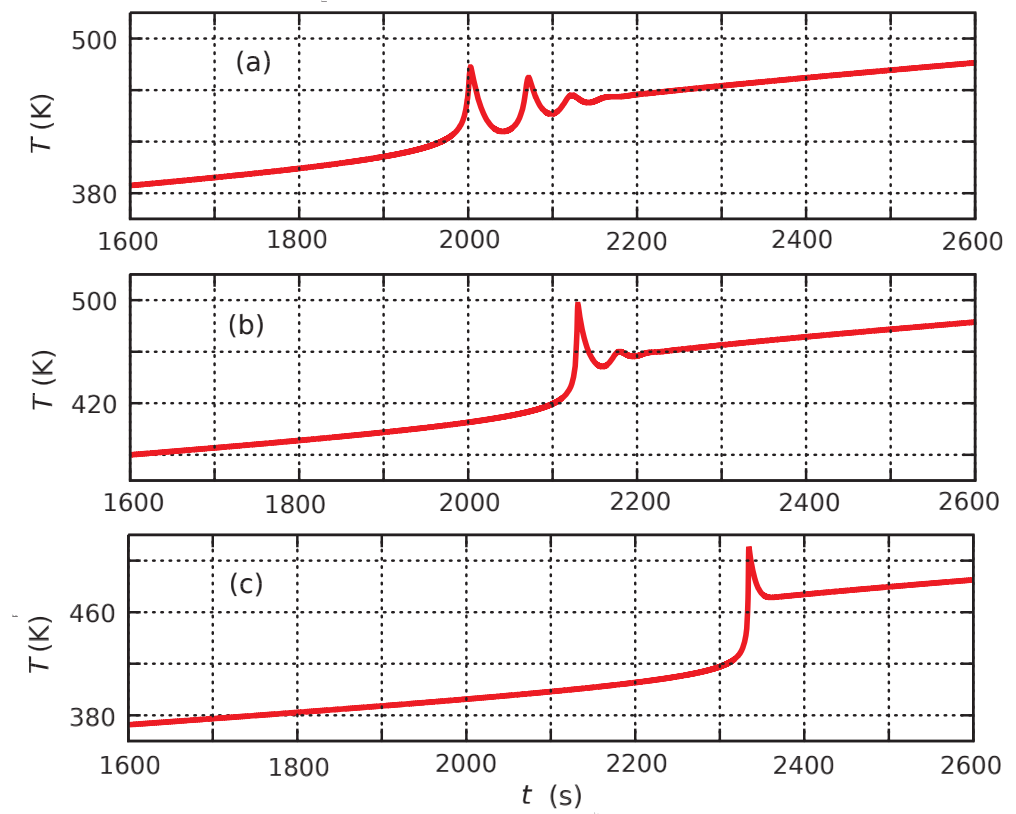

Figure 5: Time series at three values of $F$ for a drift in $\dot{q}=0.0667 \mathrm{~K} \mathrm{~s}^{-1}$ in the MEKP system of Figure 4(a). (a) $F=0.012 \mathrm{~kg} \mathrm{~s}^{-1}$, (b) $F=0.016 \mathrm{~kg} \mathrm{~s}^{-1}$, (c) $F=0.022 \mathrm{~kg} \mathrm{~s}^{-1}$. Other parameters as for Figure 4.

when the rate of flow into the reacting zone is slow and ignition is oscillatory $T_{\mathrm{a}}$, ig is relatively low; as the rate of flow increases the ignition changes from oscillatory to classical and $T_{\mathrm{a}}$, ig is relatively high. This effect is expected to be less pronounced for the lower activation energy system in Figure 4(b).

\section{Triacetone triperoxide}

In the thermolysis of cyclic triperoxides the contribution of induced decomposition is believed to be insignificant and the observed process is almost exclusively unimolecular. ${ }^{16}$ The decomposition of TATP is an interesting and complex process. It was studied by van Duin et al. $(2005)^{46}$ by molecular dynamics simulation, who found that thermal initiation of condensed phase TATP is entropy-driven, rather than enthalpy-driven, since the initial reaction, which mainly produces acetone, $\mathrm{O}_{2}$, and several unstable $\mathrm{C}_{3} \mathrm{H}_{6} \mathrm{O}_{2}$ isomers is almost energy-neutral, substantial temperature rise occurring only after the the first $50 \mathrm{ps}$ due to exothermic secondary reactions. However, the rate-determining step evidently is still peroxide oxygen-oxygen homolysis. Oxley et al. (2002) ${ }^{35}$ 
investigated the process by DSC from 151 to $230^{\circ} \mathrm{C}$ and found it first order to a high degree of conversion, and the same decomposition mechanism in toluene solution and in the gas phase.

There is disagreement in the literature as to whether pure TATP decomposes in the gas or liquid phase. Hiyoshi et al. (2007) ${ }^{47}$ found that decomposition occurred mainly in the gas phase, but Matyas and Pachman (2007) ${ }^{48}$ found that pure TATP decomposed in the liquid phase with DSC onset at $145^{\circ} \mathrm{C}$, and Ramírez et al. (2010) ${ }^{49}$ found the exotherm onset at $170^{\circ} \mathrm{C}$. The calculated normal boiling temperature in the absence of decomposition is $185 \pm 30^{\circ} \mathrm{C}$, so it is likely that both gas- and liquid-phase decomposition occur. In this work we treat the decomposition as occurring in the liquid phase.

Ramírez et al. (2006) ${ }^{50}$ obtained an enthalpy of decomposition of $-3173 \mathrm{~J} / \mathrm{g}$ by DSC $(705 \mathrm{~kJ} / \mathrm{mol})$, such a high value suggesting that oxidation of the decomposition products occurred. Dubnikova et al. (2005) $)^{51}$ used electronic structure calculations to study the energetics of TATP decomposition and found the enthalpy of decomposition (without oxidation) from the crystalline phase to be -334 to $-402 \mathrm{~kJ} / \mathrm{mol}(-1503$ to $-1809 \mathrm{~J} / \mathrm{g})$, depending on the products of decomposition. Ramírez et al. $(2006)^{50}$ determined the enthalpy of melting by DSC as $110.1 \mathrm{~J} / \mathrm{g}$. In this work I have used the average value of $-1656 \mathrm{~J} / \mathrm{g}$ and added the enthalpy of melting to obtain a value of $-1546 \mathrm{~J} / \mathrm{g}$, and computed the steady states and stability of Eqs (1) and (2) using both this value and that found by Ramírez et al. (2006). ${ }^{50}$ The kinetic parameters used are those of Oxley et al. (2002) ${ }^{35}$ starred in Table 2 , and the inflow concentration $c_{\mathrm{f}}=4.4 \mathrm{~mol} / \mathrm{kg}$ corresponds to nearly-pure TATP.

The two-parameter bifurcation diagrams are shown in Figure 6. The hook of the J-curve of Hopf bifurcations appears to be closed into a loop, but that is a trompe de l'oeil because the figures are two-dimensional projections: at the apparent crossing-point there are two temperatures. The broad regime of oscillatory behaviour overlapping and extending far beyond the classical ignition/extinction regime is, by now, expected. Note the extremely slow inflow rates, around two orders of magnitude slower than those for LP and MEKP in Figures 2 and 4 at which unstable behaviour appears. The exothermicity is more than three times that of MEKP decomposition and 2.5 times that of LP decomposition, and ingress of very small amounts of material to the reaction 

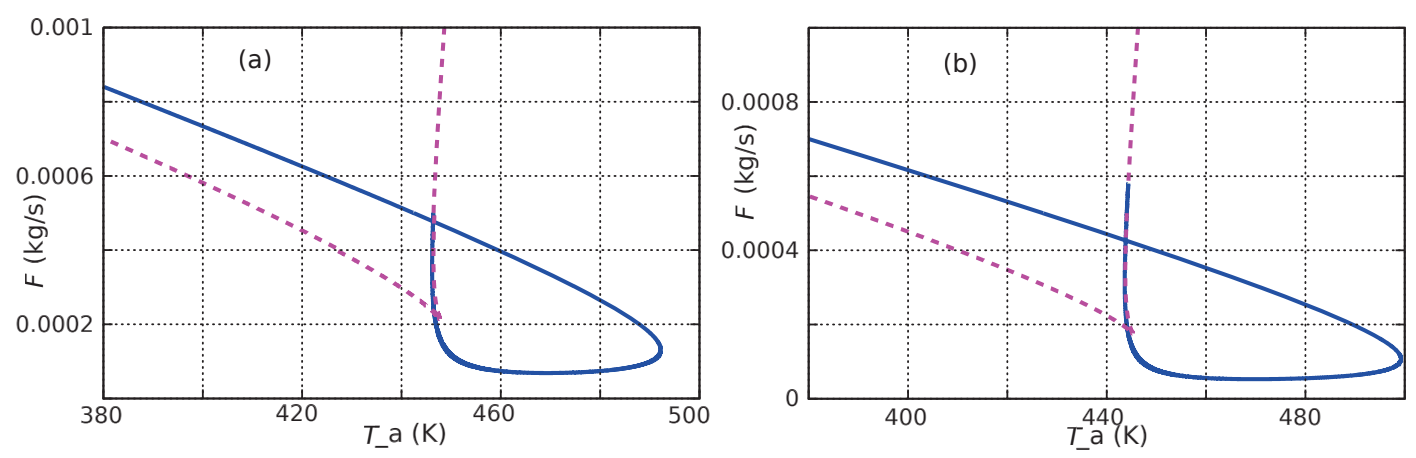

Figure 6: Loci of Hopf bifurcations (solid lines, blue in online version) and saddle-node bifurcations (dashed lines, magenta in online version) over $T_{\mathrm{a}}-F$ for decomposition of TATP in CSTR. (a) $\Delta H=-1546 \mathrm{~J} / \mathrm{g}, L=30 \mathrm{~W} / \mathrm{K}$, (b) $\Delta H=-3173 \mathrm{~J} / \mathrm{g}, L=50 \mathrm{~W} / \mathrm{K}$. Other parameters for both (a) and (b): $E=151 \mathrm{~kJ} / \mathrm{mol}, A=3.75 \times 10^{13} \mathrm{~s}^{-1}, c_{\mathrm{f}}=4.4 \mathrm{~mol} / \mathrm{kg}, T_{\mathrm{f}}=373 \mathrm{~K}$.

zone has a very large thermal effect.

\section{Thermal oscillations as a calorimetric diagnostic of an explosive liquid}

We have seen in Figure 3(a) that soft, low-amplitude thermal oscillations initially occur as the Hopf bifurcation locus is crossed at low $F$, and we know that they increase to dangerous amplitude as $F$ is increased. If a suitable calorimetric apparatus can be constructed and optimised, the potential advantages of looking for the well-behaved oscillations to diagnose a suspicious substance as likely to be a peroxide explosive are: (a) such a method method does not destroy part of the apparatus, and (b) oscillatory thermograms may be used to actually identify explosives, with suitable calibrations and validation. In particular, instrumentation can present an oscillatory signal as the Fourier transform, the resulting frequency spectrum being unique for each substance.

For pure TATP the thermal oscillations are too violent to be useful, therefore a time series from Eqs (1), (2') and (3) was computed for a $0.5 \mathrm{~mol} / \mathrm{kg}$ TATP solution in a high-boiling solvent, using a temperature ramping rate $\dot{q}=0.01 \mathrm{~K} \mathrm{~s}^{-1}$ to ensure the onset of well-behaved oscillations. The data are plotted in Figure 7. We can see in (a) that after about 25 minutes of gentle heating we can diagnose the substance as being capable of oscillatory thermal runaway. The rendering of $T$ against $T_{\mathrm{a}}$ in (b) may be regarded as a simulated thermogram.

But more is required if such a calorimetric system is to be useful in detecting peroxide explo- 

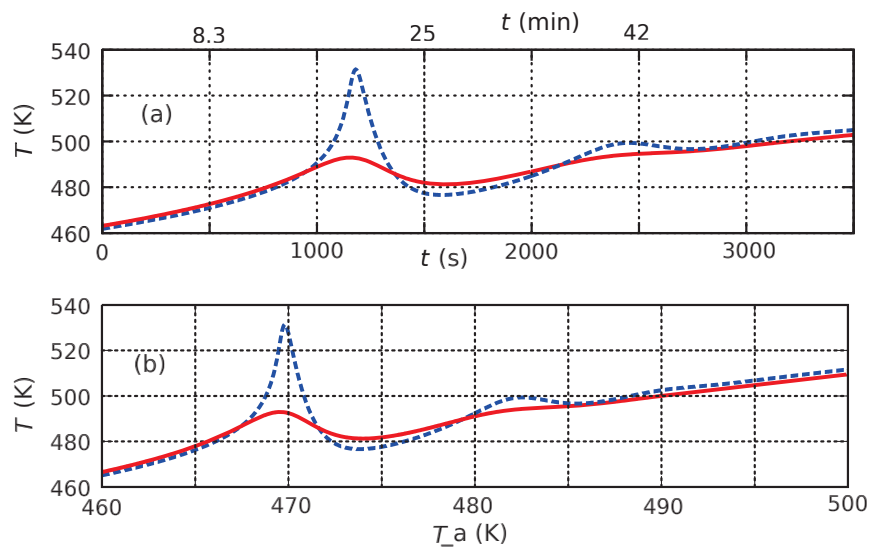

Figure 7: (a) Time series, and (b) simulated thermogram, for $\dot{q}=0.01 \mathrm{~K} \mathrm{~s}^{-1}$ in TATP diluted system. Dashed (blue) line: $F=2.0 \times 10^{-4} \mathrm{~kg} \mathrm{~s}^{-1}$, Solid (red) line: $F=1.5 \times 10^{-4} \mathrm{~kg} \mathrm{~s}^{-1}$. Other parameters as for 6 .

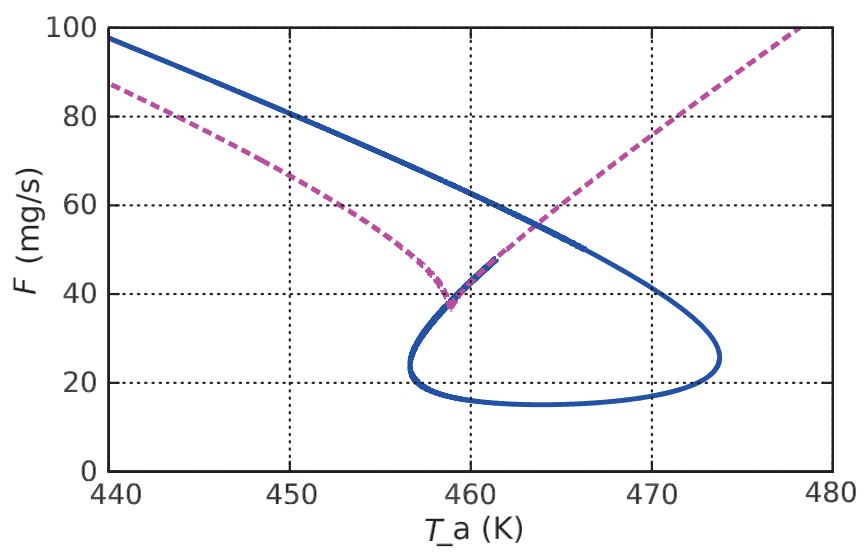

Figure 8: Loci of Hopf bifurcations (blue lines, solid) and saddle-node bifurcations (magenta lines, dashed) over $T_{\mathrm{a}}-F$ in the miniaturised TATP system. $M=500 \mathrm{mg}, L=5 \mathrm{~mW} / \mathrm{K}, E=151 \mathrm{~kJ} / \mathrm{mol}$, $A=3.75 \times 10^{13} \mathrm{~s}^{-1}, \Delta H=-1546 \mathrm{~J} / \mathrm{g}, c_{\mathrm{f}}=0.5 \mathrm{~mol} / \mathrm{kg}, T_{\mathrm{f}}=373 \mathrm{~K}, m C_{\mathrm{w}}=0.392 \mathrm{~J} / \mathrm{K}, \dot{Q}=0 \mathrm{~W}$,

sives. The device should be capable of detecting milligram to microgram quantities of a substance. The next task, therefore, is to check whether oscillatory thermal instability scales to at least the milliscale. Figure 8 was computed for the system scaled down to a reaction mixture mass of $500 \mathrm{mg}$, with the reactor mass $m$, flow rate $F$, and heat transfer coefficient $L$ scaled down proportionately, and $\dot{Q}$ regarded as negligible. We see that oscillatory thermal instability does indeed survive miniaturisation.

Figure 9 shows the simulated thermogram for the miniaturised TATP system, where $\dot{q}=0.005 \mathrm{~K} / \mathrm{s}$. This result may be regarded as an in-principle demonstration that microcalorimetric detection of 


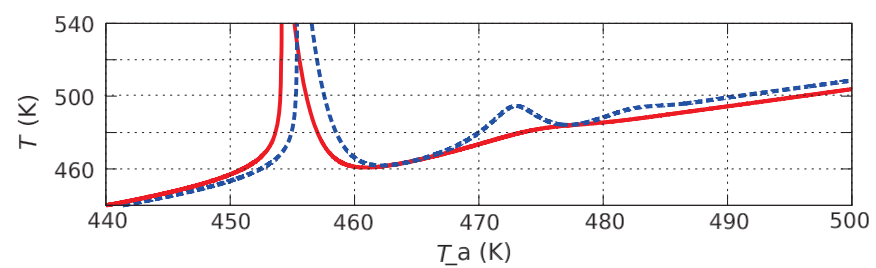

Figure 9: Simulated thermogram for miniaturised system of TATP in high-boiling diluent, with $\dot{q}=0.005 \mathrm{~K} / \mathrm{s}$. Dashed (blue) line: $F=0.1 \mathrm{mg} \mathrm{s}^{-1}$, Solid (red) line: $F=0.05 \mathrm{mg} \mathrm{s}^{-1}$. Other parameters as for Figure 8.

oscillatory thermal instability is feasible, although much experimentation would be necessary to calibrate and optimise such a system.

\section{Endex stabilization of organic peroxide decomposition}

An Endex thermoreactive system in general consists of an exothermic reaction that is directly coupled thermally and kinetically with an endothermic reaction. The original context of Endex theory and principles was building intrinsic thermal stability into reactive systems prone to thermal runaway and improving the recovery of chemical energy, ${ }^{52}$ and more recently Endex principles have been applied to $\mathrm{CO}_{2}$ capture systems. ${ }^{53}$ The ideal Endex reactor operates adiabatically, thus the exothermic reaction is exponentially cooled rather than linearly cooled and the reactions 'see' and respond to each other in real time.

The Endex CSTR equations for two thermally coupled reactor segments, each housing a single first-order reaction, are as follows:

$$
\begin{aligned}
M_{1} \frac{\mathrm{d} c_{1}}{\mathrm{~d} t} & =-M_{1} A_{1} \mathrm{e}^{-E_{1} / R T_{1}} c_{1}+F_{1}\left(c_{1, \mathrm{f}}-c_{1}\right) \\
M_{1} \bar{C}_{p, 1} \frac{\mathrm{d} T_{1}}{\mathrm{~d} t} & =M_{1}\left(-\Delta H_{1}\right) A_{1} \mathrm{e}^{-E_{1} / R T_{1}} c_{1}-\bar{C}_{p, 1} F_{1}\left(T_{1}-T_{1, \mathrm{f}}\right)-L\left(T_{1}-T_{2}\right) \\
M_{2} \frac{\mathrm{d} c_{2}}{\mathrm{~d} t} & =-M_{2} A_{2} \mathrm{e}^{-E_{2} / R T_{2}} c_{2}+F_{2}\left(c_{2, \mathrm{f}}-c_{2}\right) \\
M_{2} \bar{C}_{p, 2} \frac{\mathrm{d} T_{2}}{\mathrm{~d} t} & =M_{2}\left(-\Delta H_{2}\right) A_{2} \mathrm{e}^{-E_{2} / R T_{2}} c_{2}-\bar{C}_{p, 2} F_{2}\left(T_{2}-T_{2, \mathrm{f}}\right)-L\left(T_{2}-T_{1}\right) .
\end{aligned}
$$


Notation and quantities are defined in Appendix A, Table 6. Segment 1 houses an exothermic reaction, and segment 2 houses an endothermic reaction that is well-matched thermokinetically with the exothermic reaction. (Note that in Eqs (5) and (7) the mass capacitance of the solid parts of the reactor and the heat of stirring have been dropped, as being insignificant for the current purpose.) The thermal coupling is modelled by the last term in Eqs (5) and (7).

As a 4-variable dynamical system Eqs (4)-(7) are capable of quite baroque behaviour, including thermal chaos, ${ }^{54}$ but there is a regime in which thermal stability can be guaranteed. In the hypothetical case where kinetic and thermal matching are exact $\left(E_{1}=E_{2}, A_{1}=A_{2},\left|\Delta H_{1}\right|=\Delta H_{2}\right)$ and thermal coupling is perfect $(1 / L=0)$, and for prescribed initial conditions, Eqs (4)-(7) collapse to a integrable equation in a single dynamical variable; this perfect matching solution is $T_{1}=T_{2}=T_{\mathrm{f}}$ for all time. For real, imperfect, Endex systems it was shown by Gray and Ball (1999) ${ }^{52}$ that the perfect matching solution is an upper bound on the temperature for a broad, defined range of reaction parameter values over which the Endex reactor remains free of all thermal excursions. This important dynamical result may be stated as follows:

$$
T(t) \leq T_{\mathrm{f}} \quad \forall \quad\left(\Delta H_{2} c_{2, \mathrm{f}} M_{2}\right) /\left(\left|\Delta H_{1}\right| c_{1, \mathrm{f}} M_{1}\right) \geq 1, A_{2} / A_{1} \geq 1, E_{2} / E_{1} \leq 1 .
$$

Let us seek to stabilise the thermal decomposition of MEKP using Endex principles. Can we find a matching endothermic reaction, that at least approaches fulfilment of the conditions (8)? Other desirable properties of the endothermic reaction are that the reactants are cheap and the products are non-toxic.

Çilgi and Cetişli (2009) ${ }^{55}$ studied the thermal decomposition kinetics and thermochemistry of aluminum sulfate octadecahydrate $\left(\mathrm{Al}_{2}\left(\mathrm{SO}_{4}\right)_{3} \cdot 18 \mathrm{H}_{2} \mathrm{O}\right)$ by thermogravimetry. They found that $\mathrm{Al}_{2}\left(\mathrm{SO}_{4}\right)_{3} \cdot 18 \mathrm{H}_{2} \mathrm{O}$ decomposes to $\mathrm{Al}_{2} \mathrm{O}_{3}$ in four major stages, all endothermic, the first three being dehydrations and the final high temperature stage being sulfate decomposition. The first two dehydration stages occur from $325 \mathrm{~K}$ to $458 \mathrm{~K}$, so this may be an appropriate endothermic reaction to couple with MEKP decomposition in an Endex-configured system. For a heating rate of $4 \mathrm{~K} / \mathrm{min}$ 
the reaction enthalpy for stage II dehydration was found to be $1184 \mathrm{~J} / \mathrm{g}$ and the activation energy for stage II was $117.03 \mathrm{~kJ} / \mathrm{mol}$. Their data did not yield the frequency factor.

Using these data and the MEKP kinetic parameters of Fu et al. (2003) ${ }^{38}$ and decomposition enthalpy of Graham et al. $(2011)^{3}$ from Table 2, the first condition in (8) evaluates to 3.00, assuming $M_{1}=M_{2}$ and $c_{2, \mathrm{f}}=c_{1, \mathrm{f}}$, the second in (8) is $A_{2} / 1.77 \times 10^{13}$, and the third condition evaluates to 1.14. So, if data can be obtained that fulfils the second condition, it seems we have a workable Endex reaction couple.

For the thermokinetic data of Yuan et al. $(2005)^{39}$ in 2 the first condition in (8) evaluates to 2.45, assuming $M_{1}=M_{2}$ and $c_{2, \mathrm{f}}=c_{1, \mathrm{f}}$, the second in (8) is $A_{2} /\left(1 \times 10^{13}\right)$, and the third condition is violated because it evaluates to 0.994 . So although we cannot guarantee global stability for this Endex system it may be possible to avoid the unstable regime by manipulating $c_{2, \mathrm{f}}$, or other control parameters. In Figure 10 the steady states of Eqs (4)-(7) have been plotted as a function of $T_{2, \mathrm{f}}$ (which plays the role of $T_{\mathrm{a}}$ for the purpose of this illustration), for four values of $c_{2, \mathrm{f}}$, and using the arbitrary assumption $A_{1}=A_{2}$. Clearly, stabilization is not effective for the lower values of $c_{2, \mathrm{f}}$. Thermal coupling is effective enough to suppress much of the oscillatory instability, because the system's behaviour approaches that of an adiabatic CSTR for which periodic solutions are forbidden, but the classical ignition/extinction regime is still present. A locally stable system is obtained for $c_{2, \mathrm{f}}=0.6 \mathrm{~mol} / \mathrm{kg}$, curve $\mathbf{D}$ in Figure 10, for which the instability has been banished to impracticably high temperatures.

Decomposition is suppressed too. Table 5 compares relevant data from the dataset computed for Figure 10 and the comparable dataset computed for Figure 4.

Table 5: In the Endex system the temperature and reactant conversion are suppressed relative to the conventionally cooled system.

\begin{tabular}{lllll}
\hline \hline Figure 10: & $F$ & $T_{2, \mathrm{f}}$ & $T_{1}$ & $c_{1}$ \\
\hline & $0.01 \mathrm{~mol} / \mathrm{kg}$ & $450 \mathrm{~K}$ & $360 \mathrm{~K}$ & $9.46 \mathrm{~mol} / \mathrm{kg}$ \\
\hline Figure 4: & $F$ & $T_{\mathrm{a}}$ & $T$ & $c$ \\
\hline & $0.01 \mathrm{~mol} / \mathrm{kg}$ & $450 \mathrm{~K}$ & $459 \mathrm{~K}$ & $0.0072 \mathrm{~mol} / \mathrm{kg}$ \\
\hline \hline
\end{tabular}

We conclude that Endex stabilization using aluminum sulfate octadecahydrate shows great 

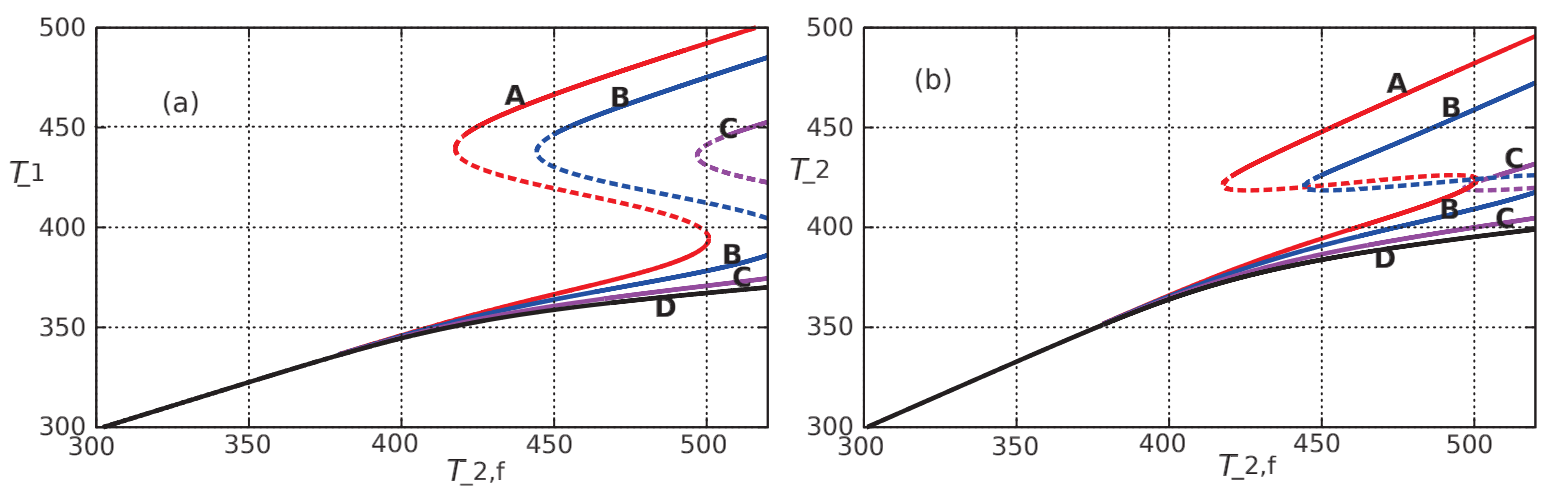

Figure 10: Bifurcation diagrams of the steady states of Eqs 4-7 over $T_{2, \mathrm{f}}$, rendered in terms of (a) $T_{1}$ and (b) $T_{2}$. The exothermic reaction is decomposition of MEKP, the endothermic reaction is decomposition of aluminum sulfate octadecahydrate. Key to the curves: A: $c_{2, f}=0.1 \mathrm{~mol} / \mathrm{kg}$, B: $c_{2, f}=0.2 \mathrm{~mol} / \mathrm{kg}, \mathbf{C}: c_{2, f}=0.4 \mathrm{~mol} / \mathrm{kg}, \mathbf{D}: c_{2, f}=0.6 \mathrm{~mol} / \mathrm{kg}$. Other parameters: $c_{1, f}=0.95 \mathrm{~mol} / \mathrm{kg}$ $F_{1}=F_{2}=0.01 \mathrm{~kg} / \mathrm{s}, L=50 \mathrm{~W} / \mathrm{K}, M_{1}=M_{2}=0.3 \mathrm{~kg}, \Delta H_{1}=-483.206 \mathrm{~J} / \mathrm{g}, \Delta H_{2}=1184 \mathrm{~J} / \mathrm{g}$, $E_{1}=117.730 \mathrm{~kJ} / \mathrm{mol}, E_{2}=117.030 \mathrm{~kJ} / \mathrm{mol}, A_{1}=A_{2}=1.77 \times 10^{13} \mathrm{~s}^{-1}, T_{1, \mathrm{f}}=298 \mathrm{~K}, C_{p, 1}=$ $2092 \mathrm{~J} /(\mathrm{kg} \mathrm{K}), C_{p, 2}=3000 \mathrm{~J} /(\mathrm{kg} \mathrm{K})$.

promise as a cheap, effective, and non-toxic method of suppressing thermal runaway in MEKP decomposition, although pressure-venting of the endothermic reaction would be necessary since hot steam is produced. For storing large quantities of MEKP it may be feasible to design a storage system with alternating cells of MEKP and aluminum sulfate octadecahydrate, or it may even be feasible to mix the two substances in the same container, but these are subjects for future experimentation.

\section{Summary, conclusions, and outlook}

The thermal decomposition of LP, MEKP, and TATP have been modelled within the CSTR paradigm, with the objective of identifying oscillatory initiation of explosive thermal runaway by stability analysis. The motivation was to improve and disseminate understanding of oscillatory ignition, in view of the large number of destructive organic peroxide incidents in industry, help counter the misuse of organic peroxides by terrorists, and improve knowledge of mathematical stability analysis in relevant sectors of the chemical engineering community.

The method of using the CSTR paradigm makes the distinction between Semenov and oscilla- 
tory thermal runaway clear. Insights into the physical origins of the oscillatory behaviour, and the interplay between kinetic and thermal effects, may be gained by mathematical two-timing analysis of Eqs (1) and (2). The details of this analysis are given in the Supporting Information. Essentially, the oscillatory behaviour occurs because liquids have high specific heat and can store the large reaction enthalpy in internal rotational modes and intermolecular vibrational modes, then release it explosively at a critical temperature determined by the activation energy. The temperature then decays because reactant is depleted, then the cycle of reaction and heat storage, rapid heat release, and temperature decay repeats.

All three substances studied were found to be capable of oscillatory thermal runaway, which occurs at lower inflow rates of reactant than classical ignition/extinction. For LP and TATP the large oscillatory J-hook, or regime where solutions are oscillatory, spreads to higher $T_{\mathrm{a}}$ than the regime of classical ignition/extinction behaviour. The presence of oscillatory thermal initiation implies that critical safety criteria evaluated using a purely Semenov approach, such as the temperature of no return, may be inadequate; and suggests new strategies for detecting explosives and safe storage of organic peroxides.

The fact that an oscillatory signal may be Fourier transformed to yield a characteristic frequency spectrum suggests that oscillatory thermal instability, in the mild regime, may be used to detect and identify explosives. A preliminary investigation produced a simulated calorimetric thermogram for TATP decomposition for a constant $T_{\mathrm{a}}$ ramp in which the mild oscillations are clearly identified. It was also shown that this behaviour survives miniaturization to the milliscale, for microcalorimetry of milligram quantities of a suspected explosive substance.

The problem of safe storage of MEKP was addressed, given that low temperature decomposition of small traces of the dimer component can cause a slow increase in the temperature of stored MEKP. In Endex stabilization, the exothermic reaction is directly coupled thermally and kinetically with a well-matched endothermic reaction. Since it was shown in Gray and Ball (1999) 52 that there exists a defined wide region of parameter space within which all thermal excursions are forbidden for all time in an Endex system, and therefore all oscillatory behavior suppressed, 
Endex stabilization seems appropriate for organic peroxides. The endothermic reaction partner for MEKP decomposition was chosen as the dehydration of aluminum sulfate octadecahydrate. Although global stability of this Endex system cannot be guaranteed, solutions of the Endex equations showed that thermal stabilization over the regime of interest is quite practicable, and that MEKP conversion is suppressed.

The simulated microcalorimetry and Endex stabilization presented here are very preliminary demonstrations of feasible concept-in-principle. Obviously, both concepts would require extensive experimental workup.

Finally, oscillatory thermal instability seems to be generic in exothermically reactive liquidphase systems (Table 1). It is real, it is not a computational artefact, it can be violent, it is dangerous to ignore it. I have not presented details of the mathematics of stability analysis, which can be found in many excellent textbooks. These are not cited here; instead, the reader is referred to the expository and resources chapter on dynamical systems and stability by Ball and Holmes (2007). ${ }^{56}$ But there are ways in which we can safely exploit this instability too. The very same instability that is responsible for the severe brisance of TATP when exploded as a terrorist weapon may also give us a novel calorimetric method of detecting and identifying it. 


\section{Appendix A}

Table 6: Definitions of quantities and notation, and numerical values of quantities where fixed (except where otherwise given in text).

\begin{tabular}{|c|c|c|}
\hline $\begin{array}{l}\text { Symbol/ } \\
\text { Quantity }\end{array}$ & Definition & Value \\
\hline$A$ & pre-exponential factor $\left((1 / \mathrm{mol})^{n-1} \mathrm{~s}^{-1}\right)$ & \\
\hline$c$ & concentration of reactant $(\mathrm{mol} / \mathrm{kg})$ & \\
\hline$C$ & specific heat capacity $(\mathrm{J} /(\mathrm{kg} \mathrm{K})$ & \\
\hline $\bar{C}$ & $\begin{array}{l}\text { temperature-average specific heat capacity } \\
(\mathrm{J} /(\mathrm{kg} \mathrm{K})\end{array}$ & 2092 \\
\hline$E$ & activation energy $(\mathrm{J} / \mathrm{mol})$ & \\
\hline$F$ & mass inflow rate $(\mathrm{kg} / \mathrm{s})$ & \\
\hline$\Delta H$ & decomposition enthalpy $(\mathrm{J} / \mathrm{g})$ & \\
\hline$L$ & combined heat transfer coefficient $(\mathrm{W} / \mathrm{K})$ & \\
\hline$m C_{\mathrm{w}}$ & heat capacity of solid parts of reactor $(\mathrm{J} / \mathrm{K})$ & 392 \\
\hline M & mass of reactant mixture $(\mathrm{kg})$ & 0.3 \\
\hline$n$ & reaction order & 1 \\
\hline$\dot{q}$ & heating rate (K/s) & \\
\hline$\dot{Q}$ & heating rate due to stirring $(\mathrm{W})$ & 30 \\
\hline$R$ & gas constant & \\
\hline$t$ & time $(\mathrm{s})$ & \\
\hline$T$ & temperature $(\mathrm{K})$ & \\
\hline \multicolumn{3}{|c|}{ Dimensionless groups (for $n=1$ ), used in the Supporting Information } \\
\hline$f$ & $F / M A$ & \\
\hline$\ell$ & $L E / c_{\mathrm{f}} M A(-\Delta H) R$ & \\
\hline$u$ & $R T / E$ & \\
\hline$x$ & $c / c_{\mathrm{f}}$ & \\
\hline$\gamma$ & $\left(M \bar{C}+m C_{\mathrm{w}}\right) /(M \bar{C})$ & \\
\hline$\varepsilon$ & $\bar{C} E / c_{\mathrm{f}}(-\Delta H) R$ & \\
\hline$\tau$ & $t A$ & \\
\hline \multicolumn{3}{|c|}{ Subscripts and superscripts } \\
\hline $\mathrm{a}$ & of the ambient or controlling temperature & \\
\hline $\mathrm{f}$ & of the inflow stream & \\
\hline ig & to or at ignition & \\
\hline 1 & of the endothermic reaction or reactor segment & \\
\hline 2 & of the endothermic reaction or reactor segment & \\
\hline
\end{tabular}

\section{Acknowledgement}

Rowena Ball is recipient of Australian Research Council Future Fellowship FT0991007. 


\section{Supporting Information Available}

Insights into the physical origins of thermokinetic relaxation oscillations may be gained by mathematical two-timing analysis of the governing equations. This material is available free of charge via the Internet at http: / / pubs. acs .org/. 


\section{References}

(1) Ho, T.-C.; Duh, Y.-S. Case studies of incidents in runaway reactions and emergency relief. Process Safetv Progress 1998, 17, 259-262.

(2) Liang, Y.-C.; Jhu, C.-Y.; Wu, S.-H.; Shen, S.-J.; Shu, C.-M. Evaluation of adiabatic runaway reaction of methyl ethyl ketone peroxide by DSC and VSP2. Journal of Thermal Analvsis and Calorimetrv 2011, 106, 173-177.

(3) Graham, S. R.; Hodgson, R.; Vechot, L.; Iqbal Essa, M. Calorimetric studies on the thermal stability of methyl ethyl ketone peroxide (MEKP) formulations. Process Safetv and Environmental Protection 2011, 89, 424-433.

(4) Burks, R. M. Current trends in the detection of peroxide-based explosives. Analvtical and Bioanalvtical Chemistrv 2009, 395, 301-313.

(5) Ball, R.; Gray, B. F. Thermal instability and runaway criteria: the dangers of disregarding dynamics. Process Safety and Environmental Protection 2012, in press, http://dx.doi.org/10.1016/j.psep.2012.05.008.

(6) Ball, R. Oscillatory thermal instability and the Bhopal disaster. Process Safetv and Environmental Protection 2011, 89, 317-322.

(7) Chang, M.; Schmitz, R. A. An experimental study of oscillatory states in a stirred reactor. Chemical Engineering Science 1975, 30, 21-34.

(8) Wirges, H.-P. Experimental study of self-sustained oscillations in a stirred tank reactor. Chemical Engineering Science 1980, 35, 2141-2146.

(9) Baccaro, G. P.; Gaitonde, N. Y.; Douglas, J. M. An experimental study of oscillating reactors. AIChE Journal 1970, 16, 249-254.

(10) Heemskerk, A. H.; Dammers, W. R.; Fortuin, J. M. H. 55 Limit cycles measured in a liquidphase reaction system. Chemical Engineering Science 1980, 35, 439-445. 
(11) Vermeulen, D. P.; Fortuin, J. M. H. Experimental verification of a model describing large temperature oscillations of a limit cycle approaching liquid phase reaction system in a CSTR. Chemical Engineering Science 1986, 35, 1291-1302.

(12) Vermeulen, D. P.; Fortuin, J. M. H. Experimental verification of a model describing the transient behaviour of a reaction system approaching a limit cycle or a runaway in a CSTR. Chemical Engineering Science 1986, 41, 1089-1095.

(13) Haldar, R.; Phaneswara Rao, D. Experimental studies on limit cycle behaviour of the sulphuric acid catalysed hydrolysis of acetic anhydride in a CSTR. Chemical Engineering Science 1991, 46, 1197-2000.

(14) Jayakumar, N. S.; Agrawal, A.; Hashim, M. A.; Sahu, J. N. Experimental and theoretical investigation of parametric sensitivity and dynamics of a continuous stirred tank reactor for acid catalyzed hydrolysis of acetic anhydride. Computers and Chemical Engineering 2011, $35,1295-1303$.

(15) Zeyer, K. P.; Mangold, M.; Obertopp, T.; Gilles, E. D. The iron (III)- catalysed oxidation of ethanol by hydrogen peroxide: A thermokinetic oscillator. Journal of Physical Chemistry A 1999, 103, 5515-5522.

(16) Antonovskii, V. L.; Khursan, S. L. Thermolysis of organic peroxides in solution. Russian Chemical Reviews 2003, 72, 939-963.

(17) Gowenlock, B. G. Arrhenius factors (frequency factors) in unimolecular reactions. Quarterly Reviews of the Chemical Society 1960, 14, 133-145.

(18) Molyneux, P. The Arrhenius parameters for the thermal decomposition of organic peroxides, and the dissociation energy of the peroxide bond. Tetrahedron 1966, 22, 2929-2943.

(19) Zou, C.-S.; Liu, J. Theoretical study on oxygen-oxygen homolytic bond dissociation en- 
thalpies of peroxides. Journal of Theoretical and Computational Chemistry 2010, 9, 625635.

(20) Duh, Y.-S.; Hui wu, X.; Kao, C.-S. Hazard ratings for organic peroxides. Process Safety Progress 2008, 27, 89-99.

(21) Oxley, J.; Smith, J. In Detection and Disposal of Improvised Explosives; Schubert, H., Kuznetsov, A., Eds.; Springer, 2006; pp 113-121.

(22) Townsend, D. I.; Tou, J. C. Thermal hazard evaluation by an accelerating rate calorimeter. Thermochimica Acta 1980, 37, 1-30.

(23) Diogo, H. P.; Minas da Piedade, M. E.; Martinho Simoes, J. A.; Nagano, Y. Standard enthalpy of formation and enthalpy of vaporization of di-1,1-dimethylethyl peroxide. Re-evaluation of the standard enthalpy of formation of the di-1,1-dimethylethoxy radical . Journal of Chemical Thermodynamics 1995, 27, 597-604.

(24) Ben Talouba, I.; Balland, L.; Mouhab, N.; Abdelghani-Idrissi, M. A. Kinetic parameter estimation for decomposition of organic peroxides by means of DSC measurements. Journal of Loss Prevention in the Process Industries 2011, 24, 391-396.

(25) Wu, S.-H.; Shu, C.-M. Reactive hazard analysis of cumene hydroperoxide and dicumyl hydroperoxide. Process Safety Progress 2010, 29, 162-165.

(26) Shen, S.-J.; Wu, S.-H.; Chi, J.-H.; Wang, Y.-W.; Shu, C.-M. Thermal explosion simulation and incompatible reaction of dicumyl peroxide by calorimetric technique. Journal of Thermal Analysis and Calorimetry 2010, 102, 569-577.

(27) Duh, Y.-S.; Kao, C.-S.; Hwang, H.-H.; Lee, W. W.-L. Thermal decomposition kinetics of cumene hydroperoxide. Trans. IChemE 1998, 76B, 271-276.

(28) Chu, Y. C.; Chen, J. R.; Tseng, J. M.; Tsai, L. C.; Shu, C. M. Evaluation of runaway thermal 
reactions of di-tert-butyl peroxide employing calorimetric approaches. Journal of Thermal Analysis and Calorimetry 2011, 106, 227-234.

(29) Tseng, J.-M.; Lin, C.-P. Green thermal analysis technology for evaluating the thermal hazard of di-tert-butyl peroxide. Industrial \& Engineering Chemistry Research 2011, 50, 94879494.

(30) You, M.-L.; Liu, S.-H., M-Y. Wu; Chi, J.-H.; Shu, C.-M. Thermal explosion and runaway reaction simulation of lauroyl peroxide by DSC tests. Journal of Thermal Analysis and Calorimetry 2009, 96, 777-782.

(31) You, M.-L.; Tseng, J.-M.; Liu, M.-Y.; Shu, C.-M. Runaway reaction of lauroyl peroxide with nitric acid by DSC . Journal of Thermal Analysis and Calorimetry 2010, 102, 535-539.

(32) Guillet, J. E.; Gilmer, J. C. Decomposition of lauroyl, decanoyl, and octanoyl peroxides in solution. Canadian Journal of Chemistry 1969, 47, 4405-4411.

(33) Li, X.-R.; Koseki, H. Thermal decomposition kinetic of liquid organic peroxides. Journal of Loss Prevention in the Process Industries 2005, 18, 460-464.

(34) Lin, C.-P.; Tseng, J.-M.; Chang, Y.-M.; Liu, S.-H.; Cheng, Y.-C.; Shu, C.-M. Modeling liquid thermal explosion reactor containing tert-butyl peroxybenzoate. Journal of Thermal Analysis and Calorimetry 2010, 102, 587-595.

(35) Oxley, J. C.; Smith, J. L.; Chen, H. Decomposition of a multi-peroxide compound: triacetone triperoxide (TATP). Propellants, Explosives, Pyrotechnics 2002, 27, 209-216.

(36) Eyler, G. N.; Mateo, C. M.; Alvarez, E. E.; Cañizo, A. I. Thermal decomposition reaction of acetone triperoxide in toluene solution. Journal of Organic Chemistry 2000, 65, 2319-2321.

(37) Chen, K. Y.; Chen, W.-T.; Chiu, C.-W.; Wu, T.-C.; Shu, C.-M. Thermal explosion simulation of methyl ethyl ketone peroxide in three types of vessel under the same volume by explosion models. Journal of Thermal Analysis and Calorimetry 2011, 106, 235-241. 
(38) Fu, Z.-M.; Li, X.-R.; Koseki, H.; Mok, Y.-S. Evaluation on thermal hazard of methyl ethyl ketone peroxide by using adiabatic method. Journal of Loss Prevention in the Process Industries 2003, 16, 389-393.

(39) Yuan, M.-H.; Shu, C.-M.; Kossoy, A. A. Kinetics and hazards of thermal decomposition of methyl ethyl ketone peroxide by DSC . Thermochimica Acta 2005, 430, 67-71.

(40) Shouman, A. R. A review of one aspect of the thermal-explosion theory. Journal of Engineering Mathematics 2006, 56, 179-184.

(41) Fine, D. H.; Gray, P.; MacKinven, R. Thermal effects accompanying spontaneous ignitions in gases. III. The explosive decomposition of diethyl peroxide. Proceedings of the Royal Society of London. Series A, Mathematical and Physical Sciences 1970, 316, 255-268.

(42) Ball, R. The origins and limits of thermal steady state multiplicity in the continuous stirred tank reactor. Proceedings of the Royal Society of London Series A 1999, 455, 141-161.

(43) Ball, R.; Gray, B. F. Transient thermal behavior of the hydration of 2,3-epoxy-1-propanol in a continuously stirred tank reactor reactor. Industrial \& Engineering Chemistry Research $\mathbf{1 9 9 5}$, $34,3726-3736$.

(44) Reimers, J. L.; Schork, F. J. Lauroyl peroxide as a cosurfactant in miniemulsion polymerization. Ind. Eng. Chem. Res. 1997, 36, 1085-1087.

(45) Milas, N. A.; Golubovic, A. Studies in organic peroxides. XXV. Preparation, separation and identification of peroxides derived from methyl ethyl ketone and hydrogen peroxide. Journal of the American Chemical Society 1959, 81, 5824-5826.

(46) van Duin, A. C. T.; Zeiri, Y.; Dubnikova, F.; Kosloff, R.; Goddard, W. A. Atomistic-scale simulations of the initial chemical events in the thermal initiation of triacetonetriperoxide. Journal of the American Chemical Society 2005, 127, 11053-11062. 
(47) Hiyoshi, R. I.; Nakamura, J.; Brill, T. B. Thermal decomposition of organic peroxides TATP and HMTD by T-jump/FTIR spectroscopy . Propellants, Explosives, Pyrotechnics 2007, 32, $127-134$.

(48) Matyas, R.; Pachman, J. Thermal stability of triacetone triperoxide. Science and Technology of Energetic Materials 2007, 68, 111-115.

(49) Ramírez, M. L.; Félix-Rivera, H.; Sánchez-Cuprill, R. A.; Hernández-Rivera, S. P. Thermalspectroscopic characterization of acetone peroxide and acetone peroxide mixtures with nitrocompounds. Journal of Thermal Analysis and Calorimetry 2010, 102, 549-555.

(50) Ramírez, M. L.; Pacheco-Londoõ, L. C.; Peña, A. J.; Hernández-Rivera, S. P. Characterization of peroxide-based explosives by thermal analysis. Proc. SPIE 6201 2006, 62012B, 1-10, DOI http://dx.doi.org/10.1117/12.666227.

(51) Dubnikova, F.; Kosloff, R.; Zeiri, Y.; Almog, J.; Zeiri, Y.; Boese, R.; Itzhaky, H.; Alt, A.; Keinan, E. Decomposition of triacetone triperoxide is an entropic explosion. Journal of the American Chemical Society 2005, 127, 1146-1159.

(52) Gray, B. F.; Ball, R. Thermal stabilization of chemical reactors. I. The mathematical description of the Endex reactor. Proceedings of the Royal Society of London Series A 1999, 455, $163-182$.

(53) Ball, R.; Sceats, M. G. Separation of carbon dioxide from flue emissions using Endex principles. Fuel 2010, 89, 2750-2759.

(54) Ball, R.; Gray, B. F. Thermal stabilization of chemical reactors. II. Bifurcation analysis of the Endex reactor. Proceedings of the Royal Society of London Series A 1999, 455, 4223-4243.

(55) Çilgi, G. K.; Cetişli, H. Thermal decomposition kinetics of aluminum sulfate hydrate. Journal of Thermal Analysis and Calorimetry (J Them Anal Calorim) 2009, 98, 855-861. 
(56) Ball, R.; Holmes, P. In Frontiers in Turbulence and Coherent Structures; Denier, J., Frederiksen, J., Eds.; Lecture Notes in Complex Systems; World Scientific, 2007; Vol. 6; Chapter 1, pp 1-27, Freely available at http://www.worldscibooks.com/chaos/6320.html, accessed 20 February 2012. 